\title{
Intrahepatic Gallbladder
}

\author{
$\underline{\text { Sherif Monib }}^{1}$, Piyush Mahapatra ${ }^{1}$, Hany Fayez Habashy ${ }^{2}$ \\ ${ }^{1}$ General Surgery Department, West Hertfordshire Hospitals NHS Trust, Hertfordshire, UK \\ ${ }^{2}$ General Surgery Department, Faculty of Medicine, Fayoum University, Egypt
}

Received: 20/04/2019

Accepted: 28/04/2019

Published: $27 / 05 / 2019$

How to cite this article: Monib S, Mahapatra P, Fayez Habashy H. Intrahepatic gallbladder. EJCRIM 2019;6: doi:10.12890/2019_001123.

Conflicts of Interests: The Authors declare that there are no competing interests.

This article is licensed under a Commons Attribution Non-Commercial 4.0 License

\section{ABSTRACT}

Gallbladders have been reported in various ectopic locations.An intrahepatic gallbladder is one where the gallbladder lies within the liver parenchyma or has a subcapsular location along the anterior inferior right lobe of the liver. Intrahepatic gallbladders can have impaired function leading to the formation of gallbladder stones. We present the case of a 57-year-old man who was found to have an intrahepatic gallbladder which was not detected before a retrograde open cholecystectomy was carried out without intra-operative or postoperative complications. Awareness of ectopic gallbladdersand their recognition allows proper intra-operative planning.

\section{LEARNING POINTS}

- Gallbladder disease in intrahepatic gallbladders poses an additional surgical risk for patients and complicates cholecystectomy or other biliary procedures.

- Awareness of this rare entity as well as optimum management will prevent patient morbidity and improve outcome.

- Preoperative MR cholangiopancreatographyis recommended if an intrahepatic gallbladder is identified on ultrasound or CT.

- Expert hepatobiliary surgeon involvement as well as an intra-operative cholangiogram is recommended in complex cases with abnormal biliary or hepatic vascular anatomy.

\section{KEYWORDS}

Gallbladder, intrahepatic gallbladder, cholecystectomy

\section{INTRODUCTION}

Congenital anomalies involving the gallbladder are very rare ${ }^{[1]}$. An intrahepatic gallbladder usually has impaired function because it does not empty completely,with many such patients developing gallstones as a result of bile stasis. Consequently, a large number of patients will require surgery, which can be problematic due to the unusual anatomy ${ }^{[2,3]}$.

\section{CASE REPORT}

We present the case of a 57-year-old manwho presented to the outpatient clinic with a 6-month history of intermittent attacks of colicky abdominal pain mainly in the right hypochondrium, radiating to the right shoulder. There was no significant past medical history. The only family history of note was that his mother had been diagnosed with breast cancer at the age of 68 .

General examination was unremarkableand all observations were stable. Abdominal examination revealed no palpable masses or organomegaly. There was mild tenderness in the right upper quadrant and epigastric region with no rebound tenderness and Murphy's sign was negative.Initial laboratory investigations including full blood count, liver function tests, and serum amylase as well as kidney function tests were all normal. 
Based on the history and clinical findings, a provisional diagnosis of gallbladder stones was suspected, so an abdominal ultrasound scan was performed. The results confirmed the clinical diagnosis, showing chronic calculous cholecystitis with a normal calibre common bile duct. The patient underwent elective laparoscopic cholecystectomy which revealed an intrahepatic gallbladder, so the operation was converted to conventional open surgery through a Kocher incision. The gallbladder was found to be intrahepatic with its fundus on the anterior surface of the liver (Fig. 1).

Retrograde cholecystectomy was carried out after resecting through the liver to separate the gallbladder from its bed (Fig. 2). The cystic duct was very long (about $8 \mathrm{~cm}$ ) and resected flush to the common bile duct as a small stone was impacted at its proximal end (Fig. 3).

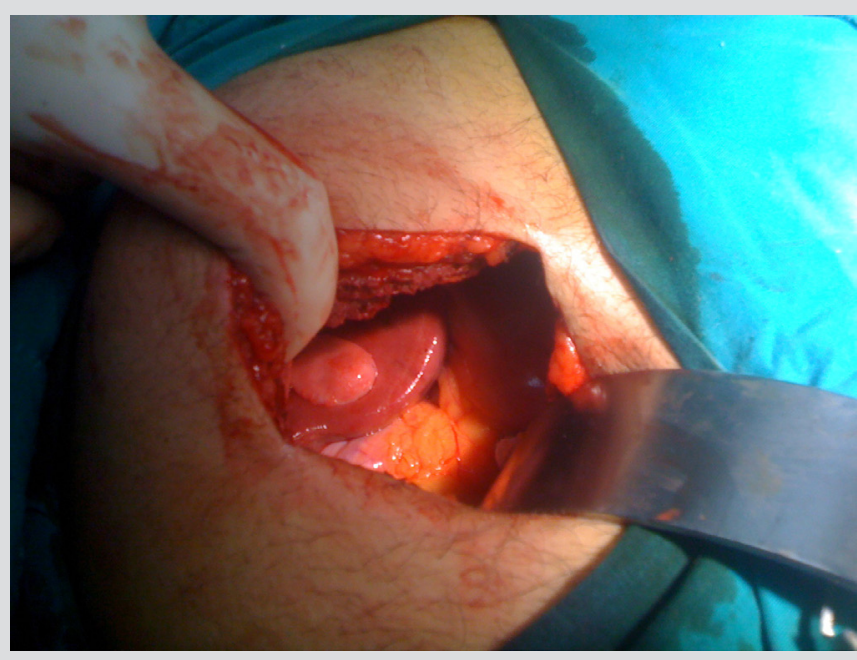

Figure 1. Intra-operative photo showing intrahepatic gallbladder with its fundus on the anteriorsurface of the liver

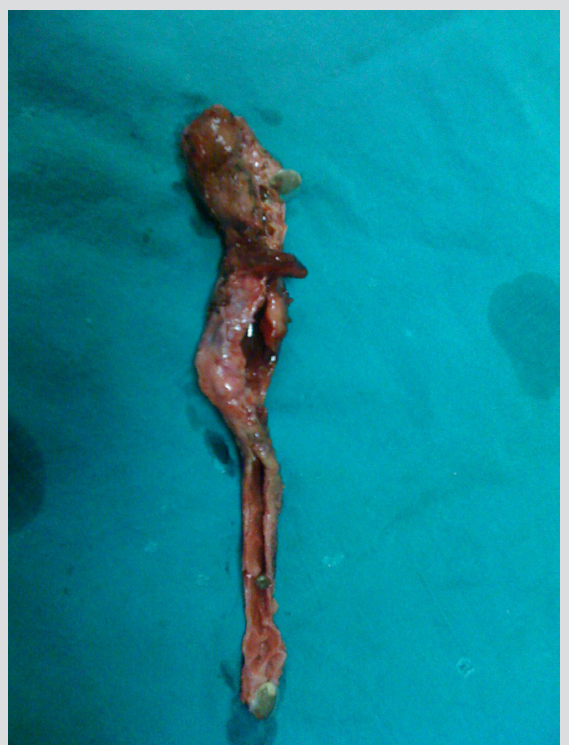

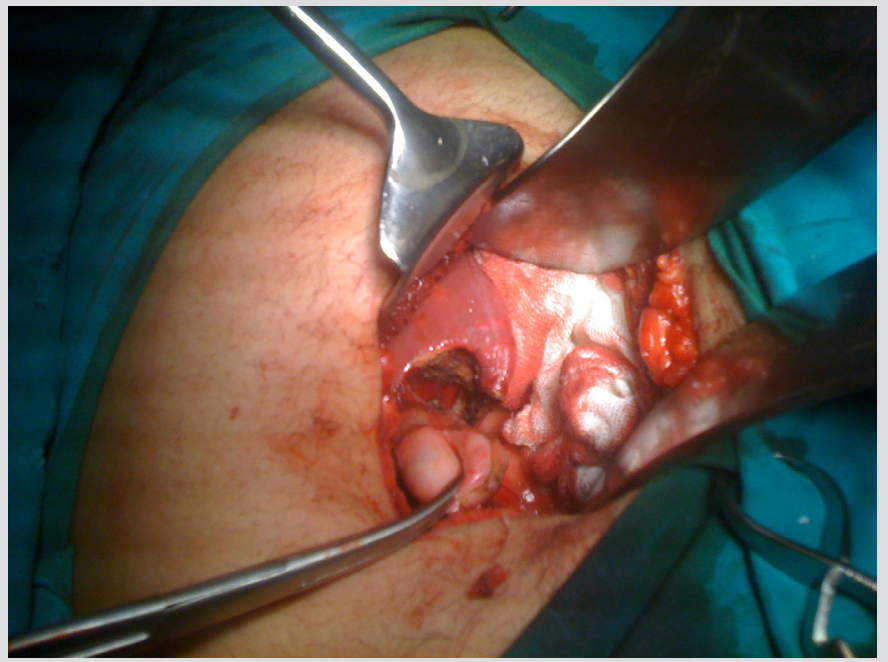

Figure 2. Intra-operative photo showing separation of the gallbladder from the liver

Figure 3. Post-operative specimen showing along cystic duct with a small stone impacted at its proximal end

After haemostasis, a size 16 tube drain was left in the operative bed, and mass abdominal wall closure was carried out.On the second postoperative day, the patient was able to tolerate fluids and a light diet, and his post-operative bloods were all within normal range. The drain only drained $40 \mathrm{ml}$ of serous fluid, so it was removed. The patient mobilized well and was discharged home after 3 days.

The patient was seen in the outpatient department 1 month later. He had continued to recover well without any recorded complications. 


\section{DISCUSSION}

Ectopic gallbladders are a very rare finding ${ }^{[4]}$ but are found in various locations:left lobe intrahepatic, transverse, retroplaced and'floating' gallbladders have all been identified. There have also been some even more uncommon case reports of a gallbladder in the falciform ligament and in the anterior abdominal wall ${ }^{[5,6]}$. The intrahepatic location is the second most common location for ectopic gallbladders ${ }^{[7]}$.

Despite its rarity, awareness of the possibility of an ectopic gallbladder is important pre-operatively. Ectopic gallbladders can have significant complications, including an increased incidence of co-existent cholelithiasis ${ }^{\left[{ }^{6}\right]}$ due to biliary stasis, risk of torsion if it is suspended on a mesentery, or even herniation through the foramen of Winslow. A significant number of such cases will therefore progress to surgery. This can lead to increased difficulties intra-operatively, particularly if there is no awareness of the possibility of an ectopic gallbladder. Although there have been case reports suggesting the importance of identifying ectopic gallbladders pre-operatively ${ }^{[7,8]}$, this unfortunately did not occur in our case, probably as a result of the intrahepatic location. However, our example demonstrates, even if the gallbladder location is identified intra-operatively, that open surgery using a retrograde approach can be performed with very successful results. Although laparoscopic cholecystectomy for ectopic gallbladders appears to be becoming increasingly common ${ }^{[9]}$, there are still no documented cases of its use in removing intrahepatic gallbladders and so open surgery should remain the treatment of choice.

\section{CONCLUSION}

Although a rare condition, an intrahepatic gallbladder will often require surgery due to the increased incidence of cholelithiasis caused by biliary stasis. Awareness of the presence of ectopic gallbladder sites and their recognition allows proper intra-operative planning to avoid possible complications.

\section{REFERENCES}

1. Faure JP, Doucet C, Scepi M, Rigoard P, Carretier M, Richer JP. Abnormalities of the gallbladder, clinical effects. Surg Radiol Anat 2008;30(4):285-290.

2. Dhulkotia A, Kumar S, Kabra V, Shukla HS. Aberrant gallbladder situated beneath the left lobe of liver. HPB (Oxford) 2002;4(1):39-42.

3. Colovic R, Colovic N, Barisic G, Atkinson HD, Krivokapic Z. Left-sided gallbladder associated with congenital liver cyst.HPB (Oxford)2006;8(2):157-158.

4. Lobo SW, Menezes RG, Mamata S, Baral P, Kanchan T, Hunnargi SA, et al.Ectopic partial intrahepatic gall bladder with cholelithiasis--a rare anomaly. Nepal Med Coll J 2007;9(4):286-288.

5. Alkatout I, Henopp T, Moritz JD, Nikischin W, Klöppel G, Engler S. Extraabdominal malposition of the gallbladder. J Pediatr Surg 2008;43(11):e41-e44.

6. Boufettal R, Khaiz D, Jai SR, Chehab F, Bouzidi A. [Right liver agenesis with ectopic gallbladder and bile duct calculi]. [Article in French] Gastroenterol Clin Biol 2008;32(4):405407.

7. Schulz RC, Shields JB, Fletcher JW, Donati RM. Liver scanning and the intrahepatic gallbladder: case report. J Nucl Med 1975;16(11):1029-1030.

8. Blanton DE, Bream CA, Mandel SR. Gallbladder ectopia. A review of anomalies of position. Am J Roentgenol Radium Ther Nucl Med 1974;121(2):396-400.

9. Chung CC, Leung KL, Lau WY, Li AK. Ectopic gallbladder revisited, laparoscopically: a case report. Can J Surg 1997;40(6):464-466. 